\title{
Irradiation of Starch and Its Effect on Pasting Properties: A Review
}

\author{
Praveen Kumar Dikkala $^{1 *}$ and S.D.S.N. Shirisha ${ }^{2}$ \\ ${ }^{1}$ Post Graduate and Research Centre, Professor Jayashankar Telangana State Agricultural \\ University, Hyderabad-500030, Telangana, India \\ ${ }^{2}$ APAC, LAM farm, Andhra Pradesh agricultural university, Guntur, Andhra Pradesh, India \\ *Corresponding author
}

\section{A B S T R A C T}

\section{Keywords \\ Irradiation of \\ Starch, \\ Carbon and \\ Energy \\ Article Info \\ Accepted: \\ 15 January 2018 \\ Available Online: \\ 10 February 2018}

Starch is the most abundant carbohydrate from the plant source.In different food processing sectors starch plays a vital role, includes thickening, gelling, consistency and shelf stability in various food applications. Irradiation plays an important role on the starch modification, it improves the viscosity of starch and plays a key role in the pasting properties. Irradiation dose was positively correlated to solubility and negatively correlated with relative crystallinity, thermal properties, and pasting properties

\section{Introduction}

Starch is the most abundant carbohydrate reserve in plants and is found in leaves, flowers, fruits, seeds, different types of stems and roots. Starch is used by plants as source of carbon and energy (Smith, 2001).In food processing industries, starch contributes a variety of vital features which includes thickening, gelling, consistency and shelf stability in varied applications (Considine and Considine, 1982). Starch can be isolated from potato, rice, corn and wheat that has been exclusively used to confer the structure, texture, consistency and appeal to many food and non-food products (Jobling, 2004). Native starches have some of the limitations such as low shear and thermal resistance as well as high affinity towards the retrogradation. The starches may need to be modified for their adaptability to the areas of application by improving the physico-chemical and functional characteristics (Bao and Corke, 2002).Biochemical chain responsible for the starch synthesis of the glucose molecules that are produced in the plant cells is by photosynthesis. Starch is formed in the chloroplasts of green leaves and amyloplasts, organelles that are responsible for the starch reserve synthesis of cereals and tubers (Smith, 
2001; Tester et al., 2004). Starch production in the chloroplasts is diurnal and performed rapidly by the plant and the starch reserves produced by the amyloplasts are deposited over several days, or even weeks. Starch is stored and cyclically and mobilized during seed germination, fruit maturation and the sprouting of the tubers (Ellis et al., 1998).

The main location of starch synthesis and storage in cereals is in the endosperm. The major sources for the starches are cereals is about 40 to $90 \%$, in roots it is about 30 to $70 \%$ in tubers it is about 65 to $85 \%$ and in legumes it is about 25 to $50 \%$ and some immature fruits like bananas or mangos, which contain approximately $70 \%$ of starch by dry weight (Santana and Meireles, 2014). The increasing pattern of starch granules in each plant tissue, shape, size, structure and composition is unique in each species (Smith, 2001).

Starch synthesized by plant cells is formed by two different types of polymers they are amylose and amylopectin. Amylopectin consists of linear chains of glucose units linked with $\alpha-1,4$ glycosidic bonds and it is highly branched at the $\alpha-1,6$ positions by small glucose chains at intervals of $10 \mathrm{~nm}$ along the molecule's axis and it constitutes in between 70 to $85 \%$ of the common starch (Durrani and Donald, 1995). Amylose contains an essential linear chain of $\alpha-1,4$ glucans with limited branching points at $\alpha-1,6$ positions and it constitutes $15-30 \%$ of the common starch. Structural starch contains chains contain amylose and amylopectin. The polymodal distribution of $\alpha$-glucans chains of different sizes and the grouping of branch points in the amylopectin molecule allow the formation of double helical chains. Amylose and amylopectin can be arranged in a semicrystalline structure forming a matrix of starch granules with alternating amorphous (amylose) and crystalline (amylopectin) material, which is known as the growth rings in superior plant starch (Jenkins et al., 1993).

\section{Physical modification of starch:}

The physical modification methods of starch is accomplished by different methods which includes the gamma irradiation, microwave (Lewandowicz et al., 2000), ultraviolet (Bertolini et al., 2001; Fiedorowicz et al., 1999), ultrahigh hydrostatic pressure (Katopo et al., 2002), and hydrothermal treatment (Jacobs and Delcour 1998). Gamma irradiation generates the free radicals on starch molecules which alter the molecular size and structures (Sabularse et al., 1991). Different studies were performed on the effects of ionizing radiation on wheat starch (Lai et al., 1959), barley endosperm and corn starch (Faust and Massey 1966; Kang et al., 1999).

In the physical method of modification of starch heat and moisture treatment is one of the major method. Different starches were subject to acid hydrolysis combined with heat and moisture treatment. In comparison with the native starches, the swelling power of all the modified corn starches decreased at different treated conditions with $75^{\circ} \mathrm{C}$ of temperature, and the solubility of the most of the modified starches were increased. The gelatinization temperature of the modified starch was increased. But Peak viscosity, trough viscosity and break down viscosity of most heat and moisture treated starch samples were lower than those of native starch. However, when $\mathrm{pH}$ was 1 , gel of starch sample was not formed. After Heat and moisture treatment, the hardness of the most modified starch gels increased significantly.

The maximum hardness of modified starch gel is about $148.419 \mathrm{~g}$ with improving about $93.471 \mathrm{~g}$ which is in comparison with native starch gel. The melting temperature of 
modified starch is increased, but the melting range is decreased in the heat and moisture treated starch. The X-ray pattern of the starch is remained practically unchanged with or without heat and moisture treatment and it can improve the physical and chemical properties of corn starch and this heat and moisture method provides some practical information on the potential usefulness of corn mixtures in the food industry (Sun et al., 2015)

\section{Chemical modification of starch}

Chemical modification is the most common way to modify the starch but there is always a concern regarding usage of the chemicals especially when they are used for different food products. Now a days the modern nonconventional methods of starch modification includes the physical techniques which are very fast, low cost and environmental friendly because they do not use pollution causing agents as well as they do not allow penetration of toxic substances in the treated products. Among all the physical techniques, irradiation is very well accepted as there is no significant rise in the temperature and it is a rapid process, non-reliance on any other type of catalysts and requires very less sample preparation. Irradiation involves the use of gamma-rays by using cobalt 60 as a source, in which the food products are directly exposed to that rays. It is an ionic non-heating processing technology which is used as an functional modification agent in polymer research and application.

Food products that are prepared by using gamma irradiation have improved durability, extended shelf life and it is nutritionally adequate and safe for the human consumption. It is responsible for inducing the several changes in starch like de polymerization and degradation which often results in the decreased viscosity and cross linking. The process of irradiation method increases the durability of foods with respect to extension of shelf-life (Chung and Liu, 2010). These changes results in the increased solubility and decrease in the swelling power and viscosity of starch. It causes hydrolysis of chemical bonds of starch into smaller fragments of dextrin, which can be either electrically charged or uncharged as free radicals. Sonication (with ultrasound) is an another method of physical treatment which is also an emerging technology that can be considered as simple, reliable, inexpensive technology and it is an environmentally friendly. Sonication is a process in which the sound waves are used to agitate particles in a solution. When the ultrasonic energy propagates in the liquid, cavitation bubbles are formed due to pressure changes. These bubbles collapse violently as the sound wave propagates, resulting into regions of high temperature and pressure. The aim of the present study was to evaluate the effect of dual modification of sonication and gamma irradiation on physicochemical and functional properties of lentil starch (Majeed et al., 2017).

Gamma irradiation degrades the glycosidic bonds which results in conversion of large starch molecules into smaller fragments. These changes may affect the physicochemical properties of the foods which are irradiated (Kang et al., 1999; Wu et al., 2002). The food products that are irradiated with gamma-irradiation have been established to be both nutritionally adequate and safe for consumption of humans (Chung and Liu., 2010; WHO, 1999). Apart from food industries, starches modified with the gamma-irradiation at higher doses are applicable in the different industries like textile and paper (Roushdi et al., 1983). The free radicals formed by the process of irradiation are involved in the formation of smaller fragments from large granules of starch by the breakdown of the glycosidic 
bonds (Yu and Wang., 2007; Sokhey and Hanna, 1993). Gamma -irradiation results the smaller fragments from the starch molecules which shows a low molecular weight change in the pasting viscosity and increase in solubility and acidity (Yu and Wang., 2007; Rayas-Duarte and Rupnow., 1993). Improvement of overall nutritional attributes and some desired changes in the functional properties of different flours have improved by using the ionizing radiations (Rahma \& Mostafa, 1988; Dario \& Salgado, 1994; Dogbevi, Vachon, \& Lacroix, 2000). The study on the irradiated foods by joint FAO/IAEA/WHO study group concluded that application of ionizing radiation at $10 \mathrm{kGy}$ or higher doses will be safe and nutritionally adequate (WHO, 1999).

\section{Changes in the starch during gamma irradiation}

Gamma irradiation is a convenient method for the modification of starch polymers through cross-linking, grafting and degradation. It is also suggested that gamma irradiation is a rapid and convenient modification technique which breaks large molecules into smaller fragments and is capable of cleaving glycosidic linkages (Kang et al., 1999; Yu and Wang, 2007) Gamma-irradiation at a dosage of $0.2-2.0 \mathrm{kGy}$ controlled the insects in packaged aromatic milled rice. Gamma irradiation induces so many physicochemical changes in the rice, decrease in the pasting parameters, increases in the water absorption capacity and total solids in the cooking water, and decreased cooked rice hardness showed the starch granules of milled rice were changed by irradiation. Several alterations on the granular structure of starch were seen with the scanning electron microscope and finally the changes in the rice affected the texture of the cooked rice (Sirisoontaralak and Noomhorm, 2006).
The main purpose of irradiation of grains and other foods is to protect them from insect infestation and microbial contamination during the period of storage. It has an important effects on various quality criteria of cereals. Different experiments havebeen performed to study the effects of irradiation on various aspects of wheat, rice, and maize quality. As we discussed earlier the depolymerization of starch by irradiation as the quality traits are mainly related to the starch properties. Free radicals produced by the irradiation modify the amount and structure of starch fractions. Granule structure remains undamaged at low dose of irradiation but it suffers severe damage at higher doses of irradiation (100 kGy). The crystallinity of the irradiated starch becomes higher with increasing the radiation doses in the starches like corn and rice. Increase in the irradiation dose is invariably associated with lower viscosity and higher water solubility and the acidity in the starch. Swelling power is generally very low, but may become higher at 20 kGyof irradiation treatment, and then declines rapidly. Gelatinization enthalpy in the grains were increased gradually with increasing the irradiation dose. The peak temperature of gelatinization became higher only at $20 \mathrm{kGy}$ on the irradiation of dry bean starch. The irradiation dose at $2 \mathrm{kGy}$ made retro gradation of lasco triticale and grana wheat starches lower and higher respectively. The chain length of amylose and amylopectin shows a progressive reduction with increase in the irradiation dosage. Gel permeation chromatographic separation clearly showed that mostly amylopectin is subject to more degradation due to irradiation (Bao and Corke, 2002).

The pasting properties of starch is changed by the gamma irradiation in the values of pasting temperature which is not a significant for lower doses (10 kGy), but above $20 \mathrm{kGy}$ irradiation dose treatment, the value of 
pasting temperature is significantly decreased. The change in the pasting temperature is not observed on the gamma irradiated starch at a dose of $500 \mathrm{kGy}$. In general, the pasting temperature, is a temperature when viscosity of starch increased sharply, was always higher than gelatinization temperature. Ultra-high irradiation dose induced by the gelatinization of starch solution is gelatinized at room temperature. The low pasting temperature of starch indicates their lower resistance towards swelling (Sandhu and Singh, 2007).

Gamma-irradiation did not change the surface structure of starch granules up to $500 \mathrm{kGy}$ of irradiation dose level. Gamma-irradiation increased the solubility of starch significantly and decreased the pasting properties such as pasting viscosity, trough viscosity, final viscosity and set back viscosity respectively. With increase in the irradiation dosage more than $50 \mathrm{kGy}$, break down viscosity decreased significantly. The decrease in setback viscosity and break down viscosity indicated that higher irradiation doses reduced the stability of starch pastes and their tendency towards the retrogradation. Upto $200 \mathrm{kGy}$ of irradiation dose and the intensity of bands corresponding to the amorphous part of the starch structure is observed to decrease. Irradiation dose was positively correlated to solubility and negatively correlated with relative crystallinity, thermal properties, and pasting properties (Liu et al., 2012)

Pasting properties such as peak, final and setback viscosities are decreased with increase in the irradiation on brown rice starch. Pasting temperature significantly decreased with increase in the irradiation in all starches. The apparent amylose content, enthalpy of gelatinization and transition temperatures, of starch decreased significantly with increase in irradiation, swelling index is decreased with increase in the irradiation dosage. Irradiation also decreased the percentage of crystallinity in the granules as the irradiation dose is increased and the surface structure was not affected. Irradiation of brown rice starch decreased the peak, setback, trough and final viscosities of the starch in which the solubility index is increased. Gamma irradiation improved some of the functional properties of the starch like decreased retrogradation, decreased gelatinization enthalpy and hence irradiation is used as an quick method for starch modification which can be used in the food industries. The reduction in the retro gradation can be very important in using the modified starch in frozen foods (Pradeep Kumar et al., 2017)

\section{References}

Abu, J. O., Muller, K., Duodu, K. G. and Minnaar, A.2006. Gamma irradiation of cowpea (Vigna unguiculata L. Walp) flours and pastes: Effects on functional, thermal and molecular properties of isolated proteins. Food Chemistry. 95:138-147.

Bao, J and Corke, H. 2002. Pasting Properties of -Irradiated Rice Starches as Affected by $\mathrm{pH}$. Journal of Agriculture and Food Chemistry. $50: 336-341$.

Bao, J., Ao, Z. and Jane, J.2005. Characterization of physical properties of flour and starch obtained from gamma irradiated white rice. Starch/Starke. 57(10):480-487.

Bertolini, A.C., Mestres, C., Colonna, P. and Raffi, J. 2001. Free radical formation in UV- and gamma-irradiated cassava starch. Carbohydrate Polymer. 44: 269-271.

Chung, H.-J., and Liu, Q. 2010. Molecular structure and physicochemical properties of potato and bean starches as affected by gammairradiation. International Journal of 
Biological macromolecules. 47: 214-222

Considine D.M. and Considine G.D.1982. Foods and Food Production Encyclopedia, Van Nostrand Reinhold Co., New York.

Dario, A. C. and Salgado, J. M.1994. Effect of thermal treatments on the chemical and biological value of irradiated and nonirradiated cowpea bean (Vigna unguiculataL. Walp) flours. Plant Foods Human Nutrition. 46:181-186.

Dogbevi, M. K., Vachon, C. and Lacroix, M.2000. Effect of gamma irradiation on the microbiological quality and on the functional properties of proteins in dry red kidney beans (Phaseolus vulgaris).Radiation Physics and Chemistry. 57:265-268.

Durrani, C. M. and Donald, A. M.1995. Physical characterisation of amylopectin gels. Polymer Gels and Networks. 3(1): 1-27.

Ellis, R. P., Cochrane, M. P., Dale, M. F. B., Duffus, C. M., Lynn, A., Morrison, I. M., Prentice, R. D. M., Swanston, J. S. and Tiller, S. A.1998. Starch production and industrial use. Journal of the Science of Food and Agriculture. 77(3):289-311.

Faust, M and Massey, Jr L.M. 1966. The effects of ionizing radiation on starch breakdown in barley endosperm. Radiation Research 29:33.

Fiedorowicz, M., Tomasik, P., Sangguan, Y. and Seung T.L. 1999. Molecular distribution and pasting properties of UV-irradiated corn starches. Starch. 51:126-131.

Franco, M.L., Preto, S.J.R., Ciacco, F.C. andTavares, D.Q.1995. Effect of the heat moisture treatment on the enzymatic susceptibility of corn starch granules. Starch-Starke. 47:233-228.

Jacobs, H. and Delcour, J.A. 1998. Hydrothermal modifications of granular starch, with retention of the granular structure: A review. Journal of Agriculture and food Food Chemistry. 46: 2895-2905.

Jenkins, P. J., Cameron, R. E. and Donald, A. M.1993. A universal feature in the structure of starch granules from different botanical sources. Stärke, 45(12):417-420.

Jobling S. 2004. Improving starch for food and industrial applications. Current Opinion in Plant Biology 7:210-218.

Kang, I. J., Byunm, M. W., Yook, H. Y., Bae, C. H., Lee, H. S., Kwon, J. H., et al., 1999. Production of modified starches by gamma irradiation. Radiation Physics and Chemistry. 54:425-530.

Katopo, H., Song, Y. and Jane, J.L. 2002. Effect and mechanism of ultra-high hydrostatic pressure on the structure and properties of starches. Carbohydrate Polymer. 47: 233-244.

Kim, S.K., Choi, H.J., Kim, K.R and Kim, H.Y. 2011.Properties of starches in Chinese yam, Dioscorea opposite Thunb. Irradiated with proton beam. Korean Journal of Plant Research. 24: 304-308.

Kim, S.K., Park, S.Y., Kim, K.R., Shin, J.H., Kim, S.Y., Kim, H.Y andLee, I.J. 2012. Effect of proton beam irradiation on germination, seedling growth, and pasting properties of starch in rice. Journal of Crop Science and Biotechnology. 15(4):305-310

Lai, S.P., Finney, K.F and Mlner, M. 1959. Treatment of wheat with ionizing radiations, oxidative, physical and biochemical changes. Cereal Chemistry. 36: 401. 
Lewandowicz, G., Janoowski, T and Fornal, J.2000. Effect of microwave radiation on physico-chemical properties and structure of cereal starches. Carbohydrate Polymer. 42: 193-199.

Liu, T., Ma, Y., Xue, S. and Shi. J.2012. Modifications of structure and physicochemical properties of maize starch by gamma irradiation treatments. LWT - Food Science and Technology 46 156-163.

Majeed, T., AhmedWani, I. and Hussain, P. R. 2017. Effect of dual modification of sonication and $\gamma$ irradiation on physicochemical and functional properties of lentil (Lens culinaris L.) starch. International Journal of Biological Macromolecules. 358365.

Mukisa, I. M., Muyanja, C. M. B. K., Byaruhanga, Y. B., Schu“ller, R. B., Langsrud, T. and Narvhus, J. A. 2012. Gamma irradiation of sorghum flour: Effects on microbial inactivation, amylase activity, fermentability, viscosity and starch granule structure. Radiation Physics and Chemistry. 81(3): 345-351.

Pradeep, K., Prakash, K.S., Kulsum, J., Tanya, L. S., Shumaila, J., Ruchi, V., Km Deepika, Dar, M. Z., Verma, K. and Khalid, B.2017.Effects of gamma irradiation on starch granule structure and physicochemical properties of brown rice starch.77: 194-200.

Rahma, E. H. and Mostafa, M. M.1988. Functional properties of peanut flour as affected by different heat treatments. Journal of Food Science and Technology. 25:11-15.

Rayas-Duarte P. and Rupnow J.1993GammaIrradiation Affects Some Physical Properties of Dry Bean (Phaseolus vulgaris) Starch. Journal of Food Science 58:389-394.

Rombo, G. O., Taylor, J. R. N. and Minnaar, A. 2004. Irradiation of maize and bean flours: Effects on starch physicochemical properties.Journal of the Science of Food and Agriculture, 84(4):350-356.

Roushdi, M., Harras, A., El-Meligi, A and Bassim, M., 1983. Effect of high doses of gamma rays on corn grains. Starch - Stärke 35:15-18.

Sabularse, V.C, Liuzzo, J.A., Rao, R.M. and Grodner, R.M. 1991. Cooking quality of brown rice as influenced by gamma irradiation, variety and storage. Journal of Food Science 56 (1): 96-98.

Sandhu, K. S., and Singh, N. 2007. Some properties of corn starches II: physicochemical, gelatinization, retrogradation, pasting and gel textural properties. Food Chemistry. 101(4): 1499-1507.

Santana, A. L. and Meireles, M. A. A.2014. New starches are the trend for industry applications: a review. Food and Public Health. 4(5):229-241.

Sirisoontaralak., P and Noomhorm A. 2006. Changes to physicochemical properties and aroma of irradiated rice. Journal of Stored Products Research. 42 (3):264-276.

Smith, A. M.2001. The biosynthesis of starch granules. Bio macromolecules. 2(2):335-341.

Sokhey, S., Hanna, M.A., Wooten, M. and Gallant, D.J.1993.Properties of irradiated starches. Food Structure. 12:397- 410.

SunQ., ZhuX., SiF., and XiongL.2015. Effect of acid hydrolysis combined with heat moisture treatment on structure and physicochemical properties of corn starch. Journal of 
Food Science and Technology 52(1): 375-382.

Tester, R. F., Karkalas, J. and Qi, X. (2004). Starch - Composition, fine structure and architecture. Journal of Cereal Science, 39(2):151-165.

World Health Organization.1999.High-dose Irradiation: Wholesomeness of Food Irradiated with Doses above $10 \mathrm{KGy}$, Report of a Joint FAO/IAEA/WHO study group. World Health
Organization Technical Report Series. 890:1-197.

Wu, D., Shu, Q., Wang, Z. and Xia, Y.2002. Effect of gamma irradiation on starch viscosity and physicochemical properties of different rice. Radiation Physics and Chemistry 65(1): 79-86.

$\mathrm{Yu}, \mathrm{Y}$ and Wang, J.2007. Effect of $\gamma$-ray irradiation on starch granule structure and physicochemical properties of rice. Food Research International. 40: 297-303.

\section{How to cite this article:}

Praveen Kumar Dikkala and Shirisha, S.D.S.N. 2018. Irradiation of Starch and Its Effect on Pasting Properties: A Review. Int.J.Curr.Microbiol.App.Sci. 7(02): 1618-1625. doi: https://doi.org/10.20546/ijcmas.2018.702.195 